\title{
Microbiologia básica por meio de ações extensionistas para alunos do Ensino
}

\section{Fundamental I e II}

\author{
Basic microbiology through extension actions for Elementary School students I and II \\ Microbiología básica a través de acciones de extensión para Estudiantes de Primaria I y II
}

\section{Resumo}

A microbiologia é o campo das ciências que estuda a morfofisiologia dos microrganismos e sua relação com o ambiente, sendo está de forma positiva e/ou negativa. O conhecimento sobre a microbiologia permite ao estudante entender a importância e as influências desses organismos em sua vida, podendo refletir na diminuição de doenças causadas por estes a partir da promoção em saúde, porém o ensino da microbiologia fica restrito a metodologias tradicionais que não possibilitam aos estudantes a visualização concreta do mesmo e sua relação com o cotidiano. Com o objetivo de sensibilizar os alunos acerca das características dos micro-organismos e avaliar seu conhecimento Este trabalho foi realizado a partir de uma ação extensionista que consistiu na elaboração de oficinas, que ofertaram várias metodologias: Datashow, teatros, gibi, atividades escritas e aulas práticas, para a melhor compreensão da microbiologia por alunos do Ensino Fundamental de 2 escolas, sendo uma do Ensino fundamental I e a outra do Ensino Fundamental II no município de Itapuranga- GO, abarcando alunos entre 8 a 15 anos do $5^{\circ}$ ao $9^{\circ}$ ano. Durante as oficinas foram utilizadas metodologias diversas, que integram o conhecimento científico com eventos cotidianos, o que instigou a interação discente-docente, com realizações de perguntas. As atividades demonstram que os alunos trazem um conhecimento prévio sobre micro-organismos, porém superficial em relação a morfofisiologia e mais profundo as doenças transmitidas.

Palavras-chave: Promoção de saúde; Material didático; Micro-organismos; Doenças.

\begin{abstract}
Microbiology is the field of sciences that studies the morphology of microorganisms and their relationship with the environment, which is positive and / or negative. Knowledge about microbiology allows the student to understand the importance and influence of these organisms in their life, and may reflect in the reduction of diseases caused by these from health promotion, but the teaching of microbiology is restricted to traditional methodologies that do not allow students to see the same and their relationship with everyday life. With the aim of sensitizing the students about the characteristics of the microorganisms and evaluating their knowledge. This work was carried out from an extensionist action that consisted in the elaboration of workshops that offered several methodologies: Datashow, theaters, comics, written activities and practical classes,for the better understanding of microbiology by Elementary School students from two schools, one of Elementary School I and the other of Elementary School II in the municipality of Itapuranga-GO, comprising students between 8 and 15 years of age from the 5th to the 9th grade. During the workshops, diversified methodologies were used, which integrated scientific knowledge with everyday events, which instigated the interaction between student and teacher, with questions asked. The activities demonstrate that the students bring a prior knowledge about microorganisms, however superficial in relation to morphophysiology and deeper transmitted diseases.
\end{abstract}

Keywords: Health promotion; Courseware; Microorganism; Illness. 


\begin{abstract}
Resumen
La microbiología es el campo de la ciencia que estudia la morfofisiología de los microorganismos y su relación con el medio, de forma positiva y / o negativa. El conocimiento sobre microbiología permite al estudiante comprender la importancia e influencias de estos organismos en su vida, lo que puede reflejarse en la reducción de enfermedades ocasionadas por ellos a través de la promoción de la salud, pero la enseñanza de la microbiología se restringe a metodologías tradicionales que no lo permiten a los estudiantes. la visualización concreta de la misma y su relación con la vida cotidiana. Con el fin de sensibilizar a los estudiantes sobre las características de los microorganismos y evaluar sus conocimientos. Este trabajo se realizó a partir de una acción de extensión que consistió en la elaboración de talleres, los cuales ofrecieron várias metodologías: Datashow, teatros, cómics, actividades escritas y prácticas de clases, para un mejor conocimiento de la microbiología por parte de estudiantes de Educación Primaria de 2 escuelas, una de la Escuela Primaria I y la otra de la Escuela Primaria II en el municipio de Itapuranga-GO, abarcando estudiantes de 8 a 15 años de $5^{\circ}$ a $9^{\circ}$ año. Durante los talleres se utilizaron diversas metodologías, que integran el conocimiento científico con los hechos cotidianos, lo que instigó la interacción alumno-profesor, con la formulación de preguntas. Las actividades demuestran que los alumnos aportan conocimientos previos sobre los microorganismos, por superficiales que sean en relación con la morfofisiología y más profundos sobre las enfermedades de transmisión.
\end{abstract}

Palabras clave: Promoción de la salud; Material didáctico; Microorganismos; Enfermedades.

\title{
1. Introdução
}

A microbiologia permitiu o descobrimento de inúmeros processos básicos referente a vida. As primeiras observações de estruturas microscópicas foram realizadas pelo inglês Robert Hook, depois com o avanço da ciência e tecnologia os estudos com esse tema foram aumentando, entre eles Antoni Van Leeuwenhoek em 1683 realizou observações de micro-organismo presentes na água da chuva, saliva, placa microbiana dos dentes e alimentos com por intermédio da microscopia (Silva \& Souza, 2013).

A microbiologia é um dos conteúdos do ensino de ciências, no qual estuda as características dos fungos, bactérias, vírus, protozoários e algas unicelulares e suas relações no desenvolvimento de doenças, processos biotecnológicos e ecológicas. O conhecimento sobre a microbiologia não é restrito ao ambiente escolar ou acadêmico, mais também para entender os processos de higiene pessoal, coletiva e as relações saúde doença tanto humana quanto animal (Ferreira, 2010; Dantas \& Ramalho, 2020).

O ensino de Ciências Naturais no Brasil passa por um processo de transformação ao longo dos anos, com a Lei $n^{\circ} n^{\circ}$ 5.692 das Diretrizes e Bases do ano de 1971, o ensino de ciências naturais passou a ser obrigatórios em todas as series do ensino fundamental, devido a necessidade dos estudantes de vivenciar as práticas do mundo científico, adquirindo o conhecimento necessário para o desenvolvimento econômico e sócio político (PCN, 1997; Sá, Silva \& Freitas, 2018).

É sabido que mudanças do ensino tradicional onde o professor é o detentor do conhecimento, transmite por meio de aulas expositivas e o aluno absorver e replica para meramente fins avaliativos está ultrapassado. O ensino deve acompanhar os avanços tecnológicos e dar condições para que os alunos identifiquem problemas e possam procurar respostam criando hipóteses, realizando experimentos e formular respostas (Carvalho, 2013; 2018). A mudança de tendência no ensino enfrenta desafios constantes, entre elas a falta de estrutura física das escolas inviabiliza a execução de aulas práticas ou experimentais que permitem a visualização de fenômenos capazes de consolidar o conhecimento. Cabe ao professor inovar e sanar os problemas que dificultam o processo de aprendizagem. Uma forma é realizar atividades práticas experimentais e lúdicas que visam a maior participação dos alunos (Pereira, et al., 2018; 2020; Parente, et al., 2020). Nos Parâmetros Curriculares Nacionais (PCNs) de 1997, ressalta que a ciência deve ter o enfoque de temas capazes de suprir as curiosidades e dúvidas dos estudantes de maneira a respeitar as características individuais e a realidade local onde a escola está inserida (Araújo \& Silva, 2012).

O ensino da microbiologia em grande parte das escolas da educação básica é ministrado com metodologias tradicionais e o conteúdo é passado de modo superficial o que não chama a atenção do educando, levando um conhecimento muitas vezes ineficiente e equivocado (Ferreira, 2010; Dantas \& Ramalho, 2020). Para Souza, et al. (2020), os micro- 
organismos são seres invisíveis ao olho nu o que torna seu estudo abstrato aos olhos das crianças que estão vivenciando seu primeiro contato com a ciência, uma vez que tudo para elas é uma nova descoberta e instiga a curiosidade visual. Para Barbosa e Oliveira, (2015), vincular as aulas teóricas e práticas abre um leque de chances para a construção do conhecimento, sendo possível o aluno observar e interagir com os modelos didáticos evidenciando a teoria de maneira prática e aplicada, bem como, visualizar os processos que envolvem os micro-organismo cria um elo entre o conhecimento do cotidiano e o conhecimento científico. Um tema dentre do Ensino de ciências e as noções básicas de higiene pessoal e coletiva, saúde e meio ambiente que é essencial para manter o bem estar a saúde do corpo (Cassanti, et al., 2006; Ferreira, 2010; Sá, Silva \& Freitas, 2018). Parente, et al., 2020).

Uma forma de contribuição entre da universidade para a sociedade são as ações extensionistas, que representa um papel importante na formação de profissionais da educação. A extensão vem ganhando a cada dia mais espaço junto a sociedade na produção e divulgação do conhecimento científico necessários para sanar a demanda da população, superando as diferenças sociais presentes, com a pratica de atividades de ensino e pesquisa (Scheidemantel, Klein \& Teixeira, 2004; Vieira \& Santos, 2020). Além de capacitar os acadêmicos para o futuro profissional, as ações extensionistas executa projetos que buscam atender as necessidades da comunidade local além de melhorar a qualidade de vida (Silva, 2009).

O presente trabalho teve como objetivo desenvolver uma ação extensionista a fim de trabalhar conceitos básicos de microbiologia (vírus, fungos, bactérias e protozoários) com aplicações de estratégias lúdicas no ensino fundamental fase I e II.

\section{Metodologia}

O presente estudo é do tipo exploratório e descritivo, com abordagem qualitativa e quantitativa dos dados, baseandose no método de Lakatos e Marconi, (1993). O estudo foi desenvolvido na cidade de Itapuranga que está localizada no Vale do São Patrício, noroeste do Estado de Goiás, há 155 km da capital Goiânia, possui bioma cerrado, sua área é de 1.276,478 Km², a população de é de aproximadamente 26.125 habitantes sendo 12.922 homens e 13.203 mulheres (IBGE 2010).

Amostra foi selecionada por conveniência, no qual foram escolhidas as seguintes escolas do município de ItapurangaGO: Escola Estadual Milton Camilo de Faria (EEMCF), que abrange os alunos do Ensino Fundamental I (EF I), sendo o $5^{\circ}$ ano o público alvo; e Escola Estadual Joaquim Da Silva Moreira (EEJSM), que abrange os alunos do Ensino Fundamental II (EF II), no qual o projeto foi realizado com todas as turmas de $6^{\circ}$ ao $9^{\circ}$ ano. Ambas as escolas autorizaram a realização do projeto assinando o Termo de Consentimento Livre e Esclarecido.

No primeiro momento foi realizado a capacitação dos discentes do curso de Licenciatura Plena em Ciências Biológicas da Universidade Estadual de Goiás, por meio da discussão de conteúdos teóricos sobre a microbiologia a fim de sanar dúvidas sobre esse conteúdo. Após a capacitação dos discentes foram confeccionados os recursos pedagógicos, que contam com: peças de teatro, cartazes, jogos, maquetes, biscuit, desenhos para colorir.

$\mathrm{Na}$ segunda etapa com o ensino fundamental fase I foram realizadas oficinas com a duração de 40/50 minutos, que foram ministradas pelos acadêmicos extensionista com a colaboração da professora vigente aplicando as atividades lúdicas pedagógicas para a interação e fixação do conteúdo, sendo realizado em 3 dias letivos. Já no ensino fundamental fase II, houve discussão sobre os temas: $1^{\circ}$ introdução a microbiologia e hábitos de higiene; $2^{\circ}$ vírus e protozoários; $3^{\circ}$ fungos e bactérias, cada tema em um dia especifico. Durante as rodas de discussão as perguntas realizadas pelos alunos foram anotadas para uma avaliação qualitativa.

A avaliação do projeto foi feita de forma contínua e observando a aprendizagem e a participação dos alunos nas oficinas, bem como a aplicação de atividades escritas e produção de textos e desenhos. Foram realizados após o termino das oficinas e ou roda de conversa uma avaliação tanto da efetividade do projeto quanto do conhecimento dos alunos sobre os temas explanados. Para o EF II foi por meio de um pequeno questionário contendo perguntas abertas, e para o EF I foi por 
meio da observação da participação dos alunos, atividades e por desenhos produzidos antes e após as intervenções.

\section{Resultados e Discussão}

\subsection{Capacitação dos discentes e montagem dos recursos didáticos}

O tripé da Universidade é o ensino, a pesquisa e a extensão, mas por muito tempo somente a pesquisa e o ensino foram alvo de discussões que originaram elaborados sistemas de avaliação da produção científica e da qualidade dos cursos (Fensterseifer \& Johann, 2021). No entanto, nos últimos anos a extensão tem ganhado espaço e visibilidade na formação acadêmica, pois um contato direto com a realidade fora do campus das universidades introduz o discente no mercado de trabalho com troca de informações entre a sociedade e a universidade (Silva \& Vasconcelos, 2006; Rodrigues, et al., 2013).

A montagem das oficinas (Figura 1) foram realizadas pelos acadêmicos extensionistas e a professora coordenadora do projeto, utilizando livros didáticos, artigos científicos, seguido por discussões para estabelecer a melhor metodologia referente a cada ano/série que seria trabalhado com intuito de usar metodologias eficazes para o processo ensino aprendizagem. Segundo Scheidemantel, Klein e Teixeira, (2004), a capacitação dos acadêmicos é fundamental para a eficácia das ações extensionistas, pois cabem a eles levarem o ensino para fora da universidade, e a realização de apresentações sobre a temática de microbiologia foi de fundamental importância para credenciar os estudantes para a realizações das oficinas.

Figura 1: Capacitação da equipe extensionista e confecção dos recursos lúdicos pedagógicos.

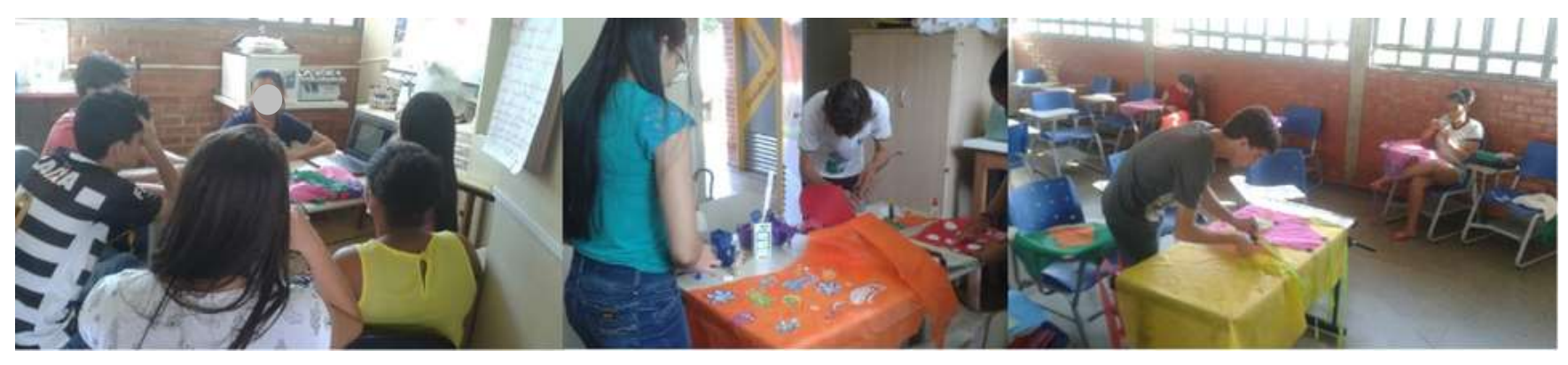

Fonte: Arquivo pessoal (2017).

\subsection{Intervenção no Ensino Fundamental I}

No dia 19 de maio de 2017, foi realizado a primeira intervenção (Figura 2) na EEMCF, com 35 discentes do $5^{\circ}$ ano com idade entre 8 a 10 anos. Primeiramente, para avaliar o conhecimento que os alunos já tinham sobre os micro-organismos foi solicitado a produção de desenhos ilustrando como eles imaginavam ser a morfologia dos fungos, bactérias, vírus e protozoários. As ilustrações mostraram que alguns educandos já tinha um conhecimento prévio formado acerca dos microorganismos como mostra a Figura 2, já na Figura 3 as ilustrações dos educandos destoam com a morfologia dos microorganismos e se aproximam da morfologia de animais e monstros animados indicando a necessidade de falar mais sobre os micro-organismos. 
Research, Society and Development, v. 10, n. 11, e54101119369, 2021

(CC BY 4.0) | ISSN 2525-3409 | DOI: http://dx.doi.org/10.33448/rsd-v10i11.19369

Figura 2: Ilustração dos micro-organismos pela imaginação dos educandos.

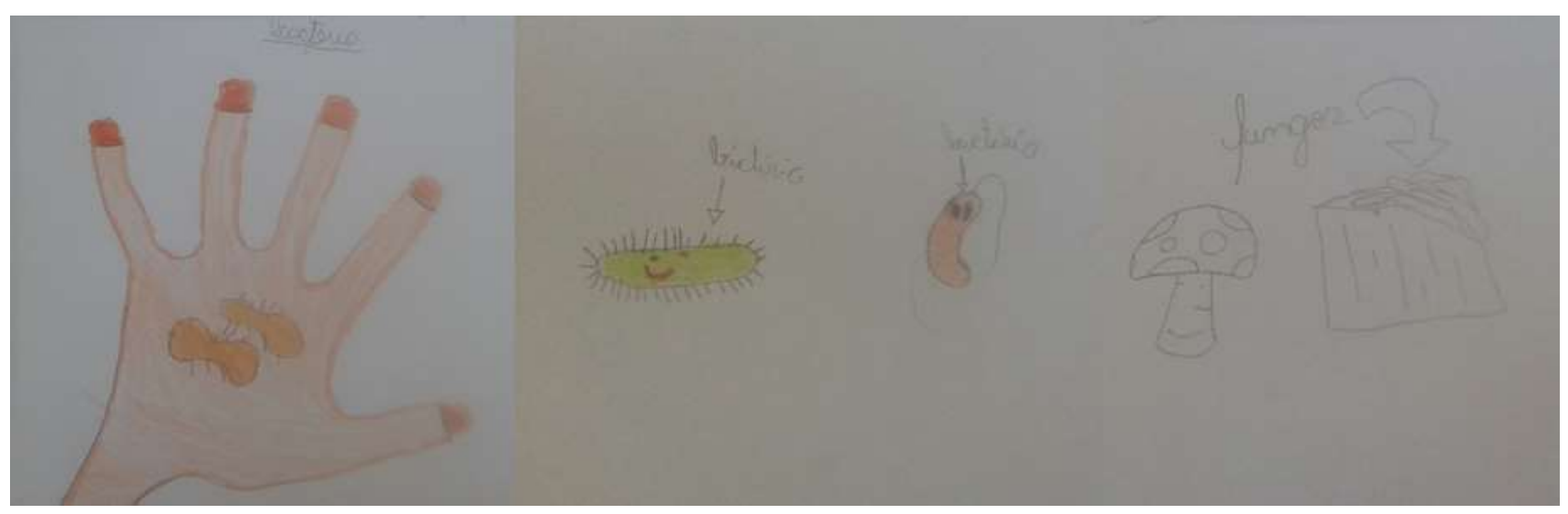

Fonte: Arquivo pessoal (2017).

Figura 3: Ilustração dos micro-organismos pela imaginação dos educandos. Fonte: Autor, 2017.

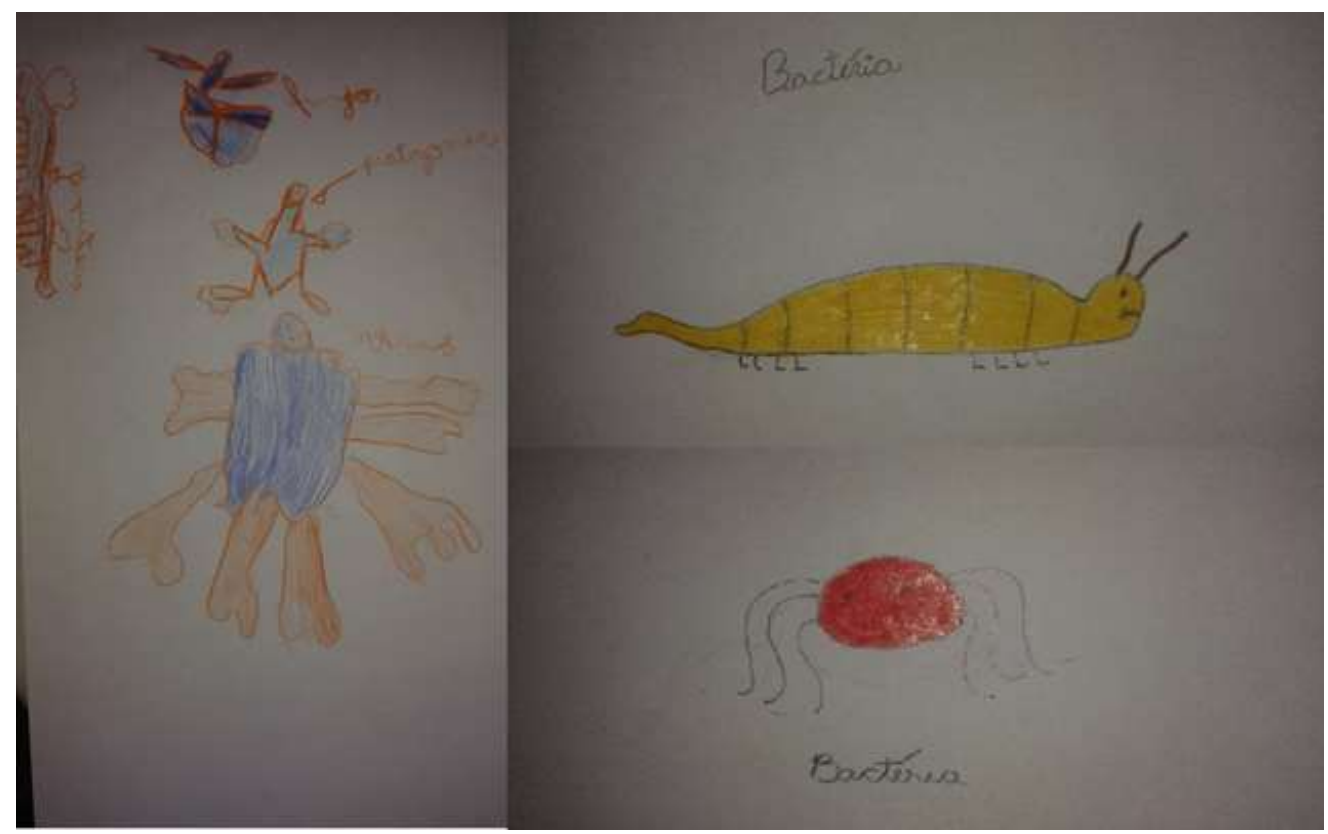

Fonte: Arquivo pessoal (2017).

Após o recolhimento dos desenhos foi realizado um teatro (Figura 4) introduzindo os tipos de micro-organismos, sua importância no ecossistema e na indústria, hábitos de higiene das mãos e as patologias que esses podem acarretar a saúde humana. 
Figura 4: Imagens do teatro e dos alunos confeccionando os desenhos no primeiro dia de intervenção na EEMCF.
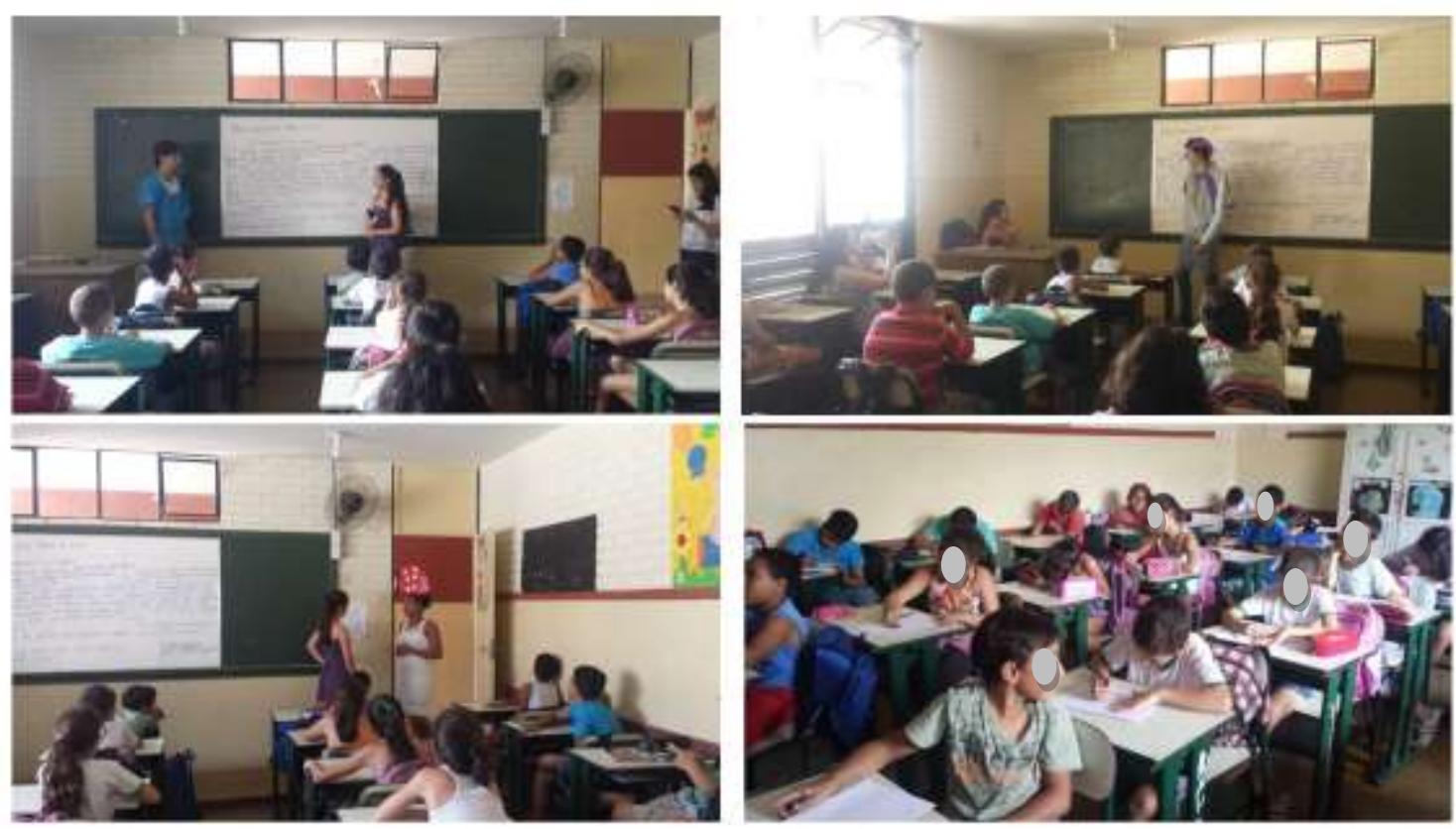

Fonte: Arquivo pessoal (2017).

Após o teatro teve um momento para que os alunos tirassem suas dúvidas, e algumas perguntas que eles fizeram estão descritas abaixo:

As Bactérias podem comer nosso sangue? Só conseguimos enxergar os micro-organismos com o microscópio? As bactérias podem matar? Todas as pessoas tem bactérias no corpo? Todas as Bactérias são do mal?

Segundo Castro e Bejarano (2017), a realização de perguntas pelos educandos são uma parte fundamental no processo de ensino-aprendizagem, pois promove a familiarização com os conteúdos gerando a atenção voluntária dos educandos pelo conteúdo, dessa maneira a criança tem um aumento significativo do aprendizado propiciado pelas experiências vividas na escola.

O ensino da microbiologia no EF I proporciona inúmeros benefícios pois os educandos dessa fase estão ávidos por aprendizado e despertar a curiosidade através do conhecimento científico, com a introdução dos micro-organismos que são seres invisíveis ao olho nu e de morfologia totalmente diferente, despertando o interesse dos educandos para noções básicas de saúde e higiene pessoal, coletiva, ambiental e no próprio aprendizado do conteúdo.

Como proposta final foi realizado uma dinâmica incentivando a higiene das mãos, no qual as mãos dos alunos foram pintadas com tinta guache e essas marcadas em um cartaz, após todos foram lavar as mãos, sendo indicados os passos para a uma higiene ideal mãos para evitar doenças causadas pelos micro-organismos (Figura 5). 
Figura 5: Realização da $1^{\circ}$ intervenção no Ensino Fundamental Fase I. Fonte: Autor, 2017. Fonte: Arquivo pessoal (2017).
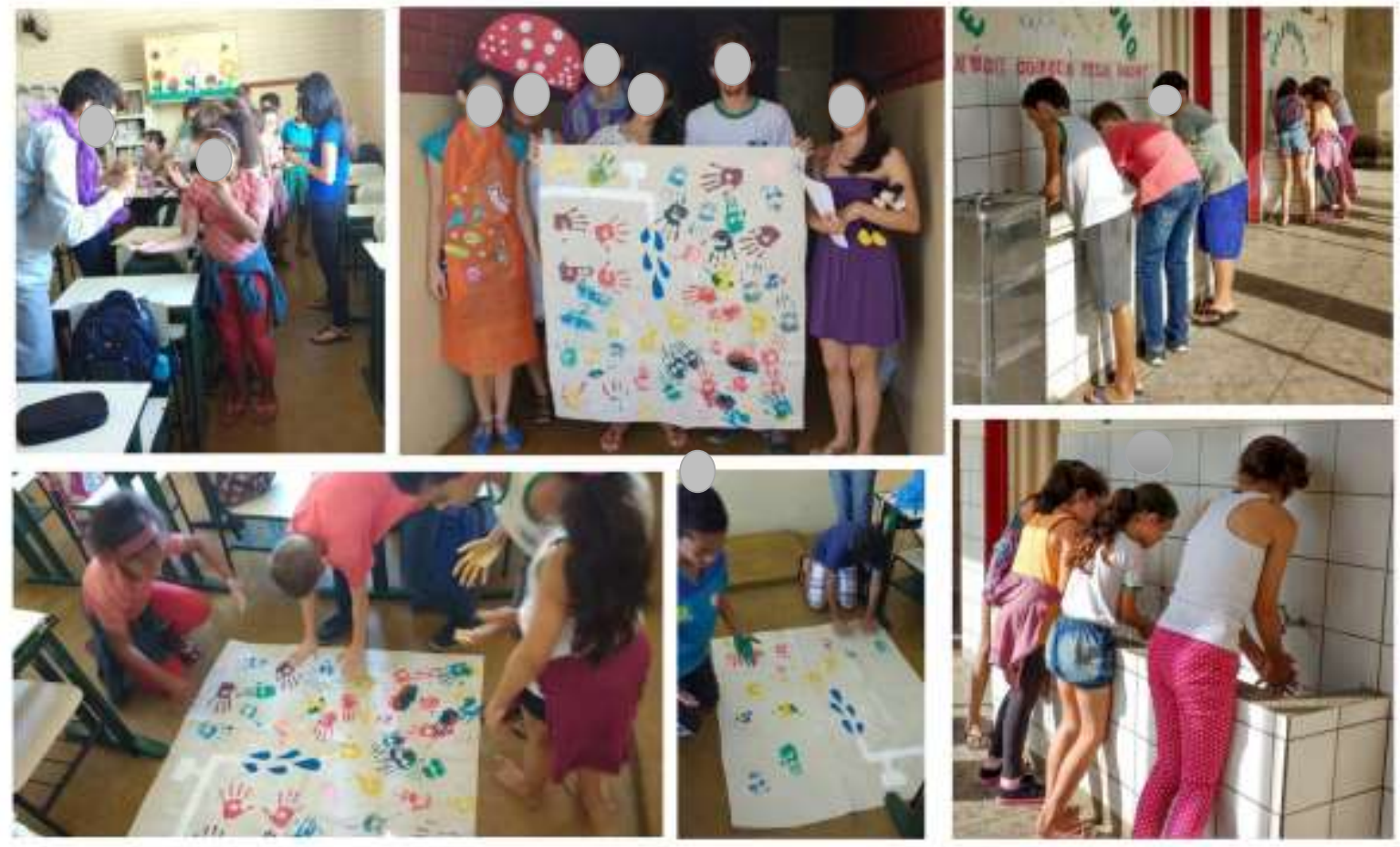

Fonte: Arquivo pessoal (2017).

Segundo Dias, Araújo e Messeder (2020), uma simples lavada de mão com o sabonete pode evitar uma infecção de micro-organismos, sendo suficiente para os contatos sociais em geral. Em um trabalho semelhante a esse projeto de extensão realizado por Jaeger (2012), com alunos do primeiro ano do Ensino Fundamental de uma escola particular, localizada na região metropolitana de Porto Alegre-RS, percebeu-se que há uma necessidade de conscientizar a comunidade escolar sobre a importância da higiene das mãos no sentido de promover a saúde, a partir de ações educativas com utilização de métodos criativos e que chamem atenção dos alunos.

No dia 06 de setembro foi realizado a segunda intervenção no EF I, com a temática vírus e protozoários, sendo realizado uma oficina com a utilização de um gibi educacional (Figura 6) sobre a morfologia, reprodução e principais doenças causadas por esses micro-organismos, assim como suas medidas preventivas.

Figura 6: Parte do gibi montado pelos acadêmicos do projeto de extensão.
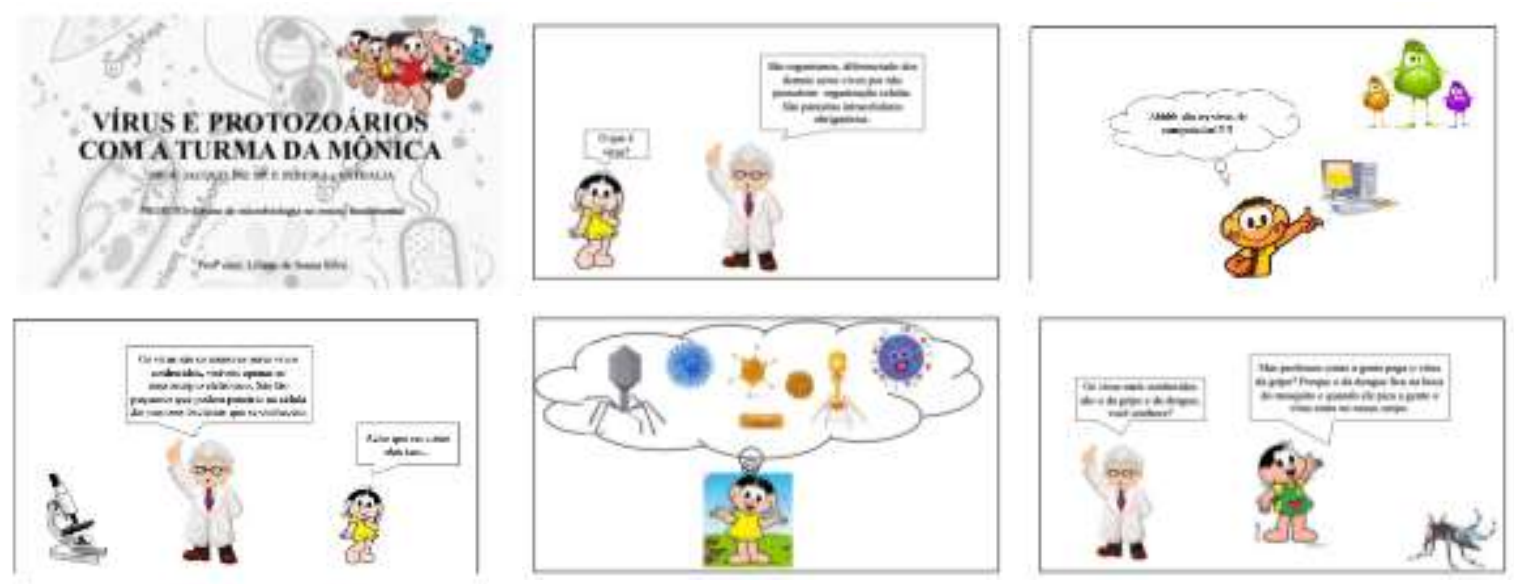

Fonte: Arquivo pessoal (2017). 
Ao decorrer da oficina os alunos do EF I fizeram as seguintes perguntas, descritas abaixo:

Qual o vírus do câncer?

Outros vírus podem gerar outro vírus?

O vírus da dengue pica uma pessoa infectada e ele vai picar outra pessoa, essa doença passa para a pessoa?

Após a oficina foi aplicado uma atividade onde os alunos escreveram texto sobre o que aprenderam durante a explicação sobre vírus e protozoários e realizaram ilustrações desses micro-organismos. Como mostra a Figura 7, as ilustrações realizadas após as oficinas estão de acordo com a morfologia dos micro-organismos que foram visualizados durante as apresentações e foram assimilados e replicados pelos os alunos nas atividades.

Figura 7: Ilustração da morfologia básica de vírus e protozoários após a oficina.

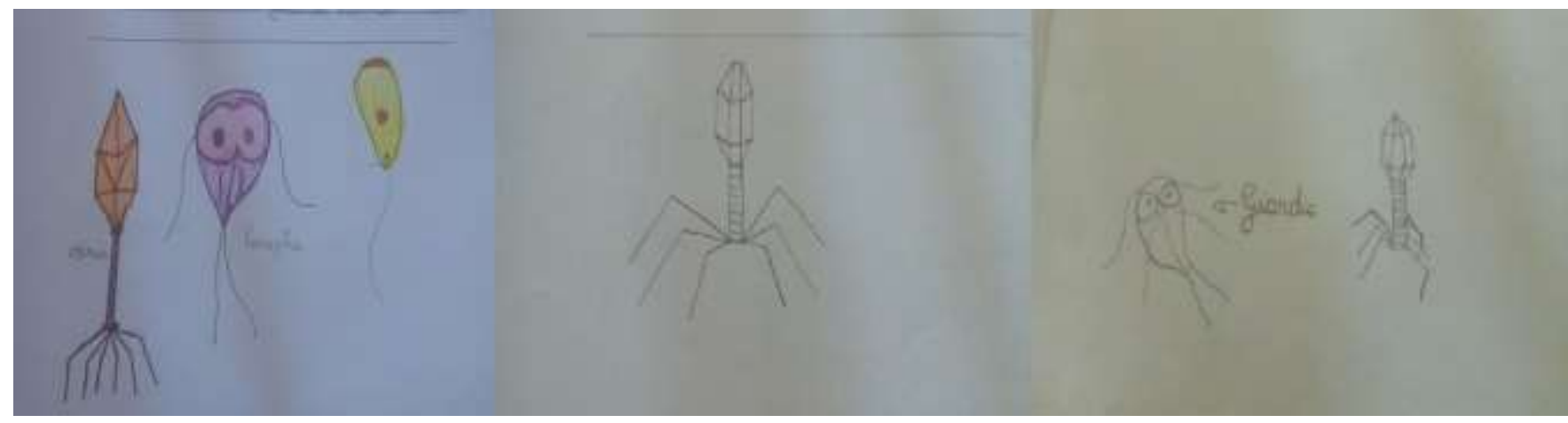

Fonte: Arquivo pessoal (2017).

Em alguns textos foram relatadas medidas preventivas sobre as doenças causadas pelos micro-organismos citados, segue trechos transcritos abaixo, escritos pelos alunos:

"Eu aprendi hoje sobre vírus e protozoários e também que nós devemos lavar as mãos antes de comer alguma coisa, e também não banhar em água contaminada. E isso eu vou levar para toda minha vida."

"Eu aprendi muitas coisas sobre vírus e protozoárias, aprendi que vírus são organismos diferentes dos seres vivos porque não possuem organização celular. Aprendi também que os protozoários tem vida livre e eles são encontrados em vários ambientes."

"Hoje eu aprendi que para um vírus criar vida é preciso ele entrar na célula. Eu aprendi que os protozoários são unicelulares (possui uma única célula).”

Já em outros textos, alguns alunos não souberam relatar sobre o que aprenderam, podendo ser a falta de interesse deles, preguiça de escrever ou a metodologia utilizada não ter os atingido. Segue abaixo trechos transcritos:

\footnotetext{
"Eu aprendi sobre vírus e protozoários."

"Vírus, protozoários e amebas."

"Eu aprendi sobre vírus, protozoários e aula de hoje foi muita boa."
}

No dia 21 de setembro de 2017 aconteceu a terceira e a última intervenção, com a temática fungos e bactérias, sendo utilizado uma aula com data show e uma exposição de fungos e bactérias ambientais não patogênicas, no qual os alunos puderam observar as morfologias das colônias (olho nú) quanto pelo microscópio. Durante a palestras foram abordados a morfologia desses organismos, sua reprodução, importância econômica e ambiental, principais doenças causadas e medidas 
preventivas. Durante a palestra os alunos fizeram perguntas, descritas abaixo:

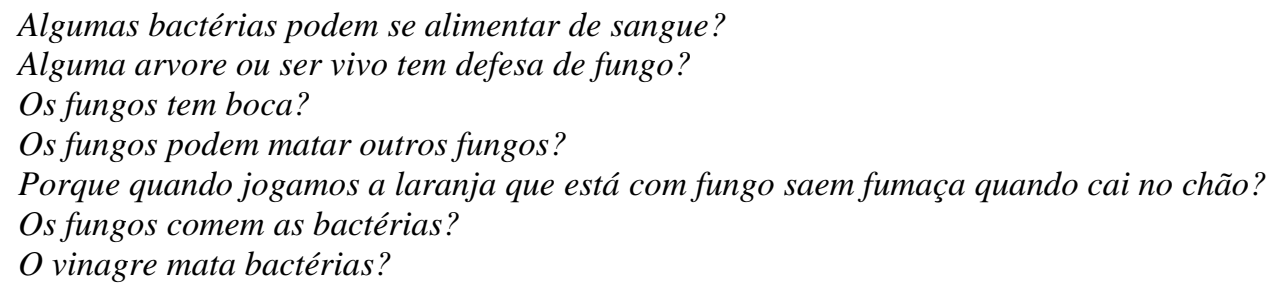

Ao termino da oficina foram aplicadas atividades sobre os fungos e bactérias para a fixação do conteúdo. Uma das atividades pedia para os alunos relatarem 'QQual a importância dos fungos e bactérias?', segue abaixo algumas respostas.

\footnotetext{
"A importância dos fungos é que eles ajudam a fermentação de iogurte, vinho e também ajudam a matar bactérias com um ácido que sai dele";

"Alguns fungos são comestíveis tipo o champiom”;
}

Foi perguntado também na atividade as doenças causadas por fungos, entre as respostas correta dos educandos estão:

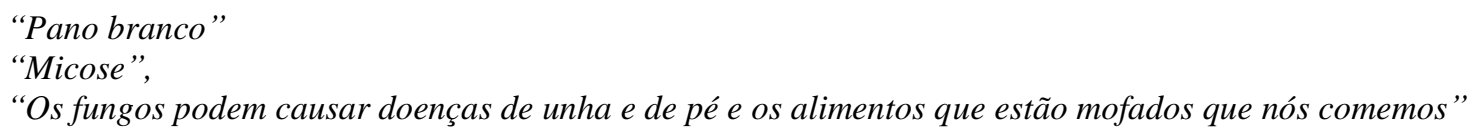

A maioria das respostas quanto a essa pergunta foi "Pano branco" e doenças de unhas o que demostra um conhecimento prévio que essas patologias são causadas por fungos, sendo as medidas preventivas dessas bem explanadas durante as explicações dos palestrantes.

Também foi perguntado, quais as doenças causadas por bactérias, nessas questões os alunos tiveram maior dificuldade sendo a resposta mais comum: "Indigestão", "Dor de garganta" e "Dor de barriga". Em relação a dor de garganta e dor de barriga são sintomas de patologias causadas por bactérias, o que demonstra que os alunos compreenderam o conteúdo de forma incompleta, já a resposta indigestão foge ao contexto de doença bacteriana, podemos relaciona-la com o fato que durante a explicação foi falado que alimentos contaminados por bactérias podem causar vomito e diarreia o que pode ter sido assimilado pelos alunos como a indigestão sendo causada por bactérias.

Como última questão foi perguntado, “onde você já viu esses micro-organismos?”. Entre as principais respostas estão: "na madeira e árvores", "no pão e na laranja”, em relação a resposta microscópio ouve a visualização de fungos e bactérias no final da intervenção, as outras respostas são a visualização que são comumente encontrados em arvores e em alimentos.

Nas oficinas foram utilizadas metodologias que levavam os alunos a relacionar o conteúdo com o cotidiano, seja através de exemplos palpáveis como o bolor nas paredes e nos alimentos, até a visualização desses micro-organismos com ou sem o auxílio do microscópio. Partindo da integração entre o conteúdo e o cotidiano, os alunos se tornaram mais participativos e realizavam frequentes perguntas com o objetivo de entender a morfologia dos micro-organismos, tornando a aula mais interativa e de certo modo informal pois os alunos se sentiam à vontade para descrever fatos vivenciados que eram relacionados ao conteúdo. O que vai de acordo com Carvalho (2013), que a formulação de pergunta permite uma maior reflexão do aluno sobre o conteúdo e suas aplicações práticas o que o torna mais significativo.

\subsection{Intervenção no Ensino Fundamental II}

Nos dias 3 e 4 de abril de 2017 foi realizada a $1^{\circ}$ intervenção na Escola Joaquim da Silva do $6^{\circ}$ ao $9^{\circ}$ ano com 120 alunos, onde foi realizado uma roda de conversa sobre importância de conhecer os micro-organismos, bem como sua 
importância ecológica e as patologias que eles podem ocasionar à saúde humana. Incentiva-los a ter bons hábitos de higiene pessoal e do ambiente em que vivem, despertando o interesse dos educandos para noções básicas de saúde e higiene pessoal, coletiva e ambiental.

Ao decorrer das palestras os alunos realizavam os seus questionamentos que estão descritos a baixo:

“O câncer tem alguma interligação com microrganismos?”
"Qual a área do corpo o tétano atinge primeiro?"
"Se o prego acabou de sair precisa vacinar?”
"Como identificar o cogumelo que não tem veneno?”
"Qual a diferença do álcool de posto e de beber?"
"O iogurte pode ser considerado um remédio?”

No dia 10 de abril de 2017 foi realizado a segunda intervenção, com a temática vírus e protozoários, sendo realizado uma oficina com a utilização de data show explicando sobre sua morfologia, reprodução e principais doenças causadas por esses microrganismos, assim como suas medidas preventivas. Ao decorrer da oficina os educandos sanaram suas dúvidas, estas estão descritas abaixo:
"O mosquito da dengue pode reproduzir o vírus da aids?"
"Os vírus também podem atingir os animais?"
"Se a gripe é um vírus, se eu pegar friagem eu vou ficar gripado?"
"A lombriga é um protozoário, porque ele fica dentro da gente?"

No dia 24 de abril de 2017 foi realizado a terceira intervenção, com a temática bactérias e fungos, com a realização de uma oficina com a utilização de data show explicando sobre sua morfologia, reprodução e principais doenças causadas por esses microrganismos, assim como suas medidas preventivas. Ao decorrer da oficina os educandos sanaram suas dúvidas, estas estão descritas abaixo:

\footnotetext{
"Então a carie é uma bactéria?"

"Toda vez que a unha ficar amarela é fungo?"

"Como faz pra matar o fungo da parede?"

"Porque não pode tomar antibiótico sempre?"
}

A quarta e última intervenção foi realizada no dia 22 de novembro de 2017, essa intervenção foi uma aula prática de todos os microrganismos estudados, onde levamos os microscópios da universidade e microrganismos do acervo do Laboratório Experimental de Biologia, contendo placas bacterianas, lâmina de protozoários e amostras de diferentes espécies de fungos.

Após a intervenção foi aplicado um pequeno questionário contendo três questões discursivas, na primeira questão foi perguntado: "O que você aprendeu sobre microrganismos?" entre as principais respostas estão: "são seres que não conseguimos enxergar sem o microscópio" e "aprendi que umas são contagiosas e podem causar doenças". Na questão dois foi perguntando: "Você gostaria de ter mais aulas práticas de ciências?" A resposta predominante foi, "gostaria de ter mais aulas práticas" e "sim, porque elas são muito legais". A terceira e última questão foi: "O projeto de microbiologia foi importante para você? Você gostaria de ter mais projetos?" Uma das respostas foram "Sim e sim, projetos assim tem finalidades importantes para o conhecimento de algumas series" e a principal resposta foi: "sim eu gostaria de ter mais projetos".

Através das explicações realizadas pelos acadêmicos extensionista relacionando a microbiologia com os assuntos cotidianos como, saúde, alimentação e biotecnologia, os educandos começaram a fazer perguntas pois perceberam que esses assuntos estão ligados ao seu dia a dia o que vai de encontro com Ferreira (2010), que as atividades práticas se manifestam de 
forma positiva ao que incumbe a microbiologia pois instigou o interesse e indagações dos educandos permitindo que relacionem questões do cotidiano de saúde e bem estar.

A importância das perguntas é para que o aluno questione mais, passando assim de uma aprendizagem passiva para uma aprendizagem ativa e significativa, e com exemplos do cotidiano, torna mais simples do aluno construer a informação e não tenha que so para memorizar para a prova (Welker, 2007). A aula prática tornou mais palpável ainda o conteúdo, pois eles poderão ver no microscópio e observar as amostras, o que os deixaram mais interessados ainda. Como Barbosa e Oliveira (2015), relatam em seu trabalho, que quando levamos algo interessante para a sala de aula, acaba se tornando um chamativo para eles.

\section{Considerações Finais}

O projeto ofereceu aos acadêmicos do curso de Ciências biológicas uma melhor capacitação professional, além do contato direto com os alunos do EF I e II o que melhora o ensino-aprendizagem que potencializa o desenvolvimento pessoal e profissional destes. Foram desenvolvidos materiais e recursos pedagógicos necessários para o desenvolvimento do projeto em todas os anos/series. Para os alunos do Ensino Fundamental essas atividades desperta um conhecimento básico de promoção em saúde. O tema microbiologia é favorável para o desenvolvimento de estratégias ativas para melhorar o processo de ensino aprendizagem no ambiente escolar e relacionar com as vivências dos discentes. Se faz necessário mais ações e projetos extensionistas que debata assuntos, ouve e esclarece questionamentos, faz demonstrações e realiza experiencias constantes na sala de aula. É possível ressaltar a necessidade de iniciativas na escola pesquisada em trabalhar com a promoção da saúde da criança. As escolas e o poder político devem desenvolver ações de promoção da educação para a saúde em meio escolar, desenvolvendo um processo em permanente e continuo. Os desenvolvimentos de várias metodologias aplicadas ao ensino de microbiologia conseguem impactar um maior número de educandos, sendo as aulas práticas uma ferramenta imprescindível para atrair a atenção dos educandos permitindo relacionar os eventos do cotidiano com o conteúdo de ciências naturais. Contudo, sugerimos maiores incentivos à formação continuada dos professores de Ciências, práticas ativas com os discentes dos cursos de licenciatura com a inserção dos mesmos desde o início da graduação no ambiente escolar, para que eles saiam da universidade preparados para planejar, desenvolver e inovar suas aulas com recursos básicos ou tecnológicos que esteja a disposição, proporcionando uma dinamização das aulas, motivando os alunos juntamente com o professor a construir o conhecimento.

\section{Agradecimentos}

Os autores agradecem a Universidade Estadual de Goiás, Câmpus Itapuranga.

\section{Referências}

Araújo, L. H. \& Silva, R. A. de O. (2012). Ensino de ciências: diagnóstico de recursos didáticos e metodológicos no processo de ensino e aprendizagem. SBEnBio - Associação Brasileira de Ensino de Biologia. Goiânia.

Barbosa, F. G. \& Oliveira, N. C. (2015). Estratégias para o ensino de microbiologia: uma experiência com alunos do ensino fundamental em uma escola de Anápolis-GO. UNOPAR Cient., Ciênc. Human. Educ. Londrina. 16, p. 5-13.

Brasil. (1997). Secretaria de Educação Fundamental. Parâmetros curriculares nacionais: ciências naturais. Secretaria de Educação Fundamental. - Brasília: $\mathrm{MEC} / \mathrm{SEF}, 136 \mathrm{p}$.

Carvalho, A. M. P. (2013) Formação de Professores de Ciências: duas epistemologias em debate. In: IX Congreso Internacional sobre Investigación em Didática de Las ciências, Girona.

Carvalho, A. M. P. (2018) Fundamentos Teóricos e Metodológicos do Ensino por Investigação. Revista Brasileira de Pesquisa em Educação em Ciências. 18 (3), 765-794.

Castro, D. R. \& Bejarano, N. R. R. (2017). Compreensão dos estudantes do ensino fundamental I sobre estrutura e funcionalidade micro-organismos/células. Experiências em Ensino de Ciências. 12 (3), 93-115. 
Cassanti, A. C., Cassanti, A. C., Araujo, E. \& Ursi, S. (2008). Microbiologia democrática: estratégias de ensino aprendizagem e formação de professores. Enciclopédia Biosfera, 4(5). https://conhecer.org.br/ojs/index.php/biosfera/article/view/4929.

Dantas, É. de F. \& Ramalho, D. F. (2020) The use of different methodologies in the teaching of microbiology: A systematic literature review. Research, Society and Development, [S. 1.], v. 9, n. 8, p. e665986396. DOI: 10.33448/rsd-v9i8.6396.

Dias, G. S., Araújo, F. M. B. \& Messeder, J. C. (2020) Let's wash our hands, shall we? Teaching science through songs. Research, Society and Development. 9(8), e720986110. DOI: 10.33448/rsd-v9i8.6110.

Fensterseifer, P. E. \& Johann, M. R. (2021). The indissociability of teaching, research and extension: a practical issue. Research, Society and Development, [S. l.], v. 10, n. 1, p. e36210111795. DOI: 10.33448/rsd-v10i1.11795.

Ferreira, A. F. (2010). A importância da microbiologia na escola: Uma abordagem no ensino médio. Monografia (licenciatura plena em ciências biológicas). Universidade do Estado do Rio de Janeiro. Rio de Janeiro.

IBGE. Censo Demográfico 2010 - Características Gerais da População. Resultados da Amostra. IBGE. http://www.ibge.gov.br/ home/estatistica/ populacao/cnso2010/default_populacao.shtm.

Jaeger, H. M. M. (2012) A lavagem das mãos no cotidiano da escola: uma atitude de promoção da saúde. $2012.31 \mathrm{f}$. Trabalho de Conclusão de Curso (Especialização em Informação Científica e Tecnológica em Saúde) - Instituto de Comunicação e Informação Científica e Tecnológica em Saúde, Fundação Oswaldo Cruz; Grupo Hospitalar Conceição, Porto Alegre, RS.

Lakatos, E. M. \& Marconi, M. A. Fundamentos de metodologia científica. São Paulo: Atlas, 1993.

MIMS, Cedric. Microbiologia Medica. 3 ed. Rio de Janeiro: Elservier, 2005.

Parente, F. de S.; Oliveira, R. C. M.; Santos, L. C. M. dos; Tsukimata, M. Y.; SILVA, J. M. R.; Sacramento, R. da C.; Vasconcelos, L. A. de; Pereira, C. E. A.; Sousa, J. S. \& Lopes, L. de J. S. (2020). Health Education: a socio-educational tool for health promotion for children in a public school in Belém do Pará, Brazil. Research, Society and Development, [S. 1.], v. 9, n. 7, p. e208973896. DOI: 10.33448/rsd-v9i7.3896.

Pereira, R. J. B., Aguiar, A. S., Sousa, E. T. F., Hager, A. X., \& Azevedo, M. M. R. R. (2018). Avaliação de três metodologias de ensino em biologia na modalidade EJA em escolas do município de Santarém-PA. Revista Eletrônica de Educação da Faculdade Araguaia, 13(2), 1-10.

Pereira, R. J. B., Azevedo, M. M. R. R., Sousa, E. T. F., \& Hager, A. X. (2020). Método tradicional e estratégias lúdicas no ensino de Biologia para alunos de escola rural do município de Santarém-PA. Experiências em Ensino de Ciências, 15(2), 106-123.

Rodrigues, L. L., Prata, M. S., Batalha, T.B.S., Costa, C.L.A. \& Passos Neto, I. F. (2013). Contribuições da Extensão Universitária na Sociedade. Cadernos de Graduação - Ciências Humanas e Sociais, 1 (16), 141-148.

Scheidemantel, S. E., Klein, R. \& Teixeira, L. I. (2004). A importância da extensão universitária: o projeto construir. Anais do $2^{\circ}$ Congresso Brasileiro de Extensão Universitária. Belo Horizonte.

Silva, E. R. \& Souza, A. S. (2013). Introdução ao estudo da microbiologia: Teoria e pratica. Brasília: Editora do IFB, 2013.

Silva, R. A. (2009) A extensão como método de ensino teórico-prático no ensino superior. EDUCERE - Revista da Educação, Umuarama, v. 9, n. 2, p. 119137.

Rodrigues, L. L., Prata, M. S., Beatriz, T., Batalha, S., Costa, A., Neto, F. P., Impresso, E. I., \& Eletr, I. (2013). Contribuições da Extensão Universitária na Sociedade. Cadernos de Graduação - Ciências Humanas e Sociais, 1(16), 141-148.

Sá, C. A. de, Silva, K. R. de C., \& Freitas, V. S. (2018). O ensino de microbiologia nas escolas públicas de ensino fundamental do município de Jaguaribe, Ceará. Conexão Ciência. e Tecnologia. Fortaleza/CE, v.12, n. 1, p. 84 - 96. DOI: 10.21439/conexoes.v12i1.1380

Silva, M. do S. \& Vasconcelos, S. D. (2006). Extensão Universitária e Formação Profissional: avaliação da experiencia das Ciências Biológicas na Universidade Federal de Pernambuco. Estudos Em Avaliação Educacional, 17(33), 119-136.

Souza, M., Viana, D. R., Fantti, M. F., Maidana Junior, J. N., Stopiglia, C. D. O., Ribeiro, V. B. (2020) Divulgando conceitos de microbiologia na escola. Anais do Salão Internacional de Ensino, Pesquisa e Extensão, v. 7, n. 3, 14 fev. 2020.

Tortora, G. J., Funke, B. R., Case, C. L. (2005) Microbiologia. 8 ed. Porto Alegre: Artmed.

Welker, C. A. D. (2007). O Estudo de Bactérias e Protistas no Ensino Médio: Uma Abordagem Menos Convencional. Universidade Federal do Rio Grande do Sul, Porto Alegre.

Vieira, T. D. G. F..; Santos, M. L. S. C. dos. (2020). University extension and applicability of active methodologies in the Baixada Fluminense community. Research, Society and Development, [S. l.], v. 9, n. 11, p. e2769119750. DOI: 10.33448/rsd-v9i11.9750. 